\title{
The production of social science research in Nigeria: status and systemic determinants
}

\author{
Abiodun Egbetokun (1) ${ }^{1 凶}$, Adedayo Olofinyehun (1) ${ }^{1}$, Maruf Sanni (i) ${ }^{1}$, Aderonke Ayo-Lawal (1) ${ }^{1}$, \\ Omolayo Oluwatope ${ }^{1} \&$ Utieyineshola Yusuff (i) ${ }^{1}$
}

Nigeria has a very large research system, with nearly 200 universities that employed more than 60,000 academic staff at the end of 2019. The country is also one of Africa's largest producers of scientific research across all disciplines, surpassed only by South Africa and Egypt. In the social sciences, in particular, Nigeria is Africa's second-largest producer of published research, after South Africa. However, the country's social science research (SSR) production does not match the size of its SSR system. Using mixed methods, we come up with two important reasons for this: (i) research inputs are low, mainly because research is poorly funded and researchers devote too little time to research as a result of poor organisational climate, and (ii) the research support system is weak. No single institution currently has a clear mandate to centrally coordinate SSR in Nigeria. Consequently, research efforts are often duplicated and the limited research resources are spread too thin. Moreover, logistical support for research is missing or inefficient in most organisations. Therefore, improving research productivity in the country would require much stronger research coordination and wide-ranging improvements in the research climate.

\footnotetext{
${ }^{1}$ National Centre for Technology Management, Ile-Ife, Nigeria. ${ }^{凶}$ email: aaegbetokun@gmail.com
} 


\section{Introduction}

ocial science started to be recognised as a distinct subject area in the nineteenth century (Thompson, 1824). Today, the expression 'social science' or 'social sciences' is applied to the branch of science concerned with society and human behaviours. It includes disciplines such as psychology, cognitive sciences, economics, business, education, sociology, law, political science, social and economic geography, media and communications, and interdisciplinary social sciences (OECD, 2015). Social science research (SSR) helps in understanding and developing solutions to complex developmental challenges including climate change, pandemics, poverty, unemployment and others.

More specifically, SSR provides knowledge that is fundamental to the formulation and realisation of development agendas and policies, without which other branches of science are of limited use. For instance, "[s]cientific and technological innovations are necessary, but enabling them to make an impact requires an understanding of how people adapt and change their behaviour. That will probably require new narratives-the purview of rhetoric, literature, philosophy and even theology. Poverty and inequality call even more obviously for expertise beyond science and maths" (Shah, 2020).

Clearly, achieving the development agenda at the national level requires significant domestic SSR capacity. This helps to ensure that scientific evidence is generated based on critical analyses of each country's social, development and policy challenges. Such evidence will help to inform contextually relevant actions and reforms. This is particularly important in developing countries which collectively are disproportionately affected by most of today's development challenges. However, little is known about SSR capacity in developing countries, particularly in Africa. This is largely due to the absence of reliable system-wide data in most of these countries. Against this background, this paper analyses the production of SSR (that is, the quantity of SSR produced in Nigeria, its quality in terms of peer review and accessibility in terms of open access) and explores the systemic factors that influence its volume and quality in Nigeria.

The case of Nigeria is instructive for two reasons, at least. First, a thorough understanding of SSR production in Africa will benefit from an analysis of the Nigerian context given the country's geographical and economic size. Nigeria is the largest country in Africa, both by population and gross domestic product (GDP). It is also one of the largest producers of SSR on the continent (AU-NEPAD, 2010). Secondly, although Nigeria has a very large SSR system, including a well-organised university system where most of the SSR research takes place, its research productivity does not match its size. For instance, while Nigeria has roughly five times as many universities as South Africa, its aggregate research output from all disciplines is just over a third of South Africa's (Mba and Ekechukwu, 2019). This begs two questions that this paper seeks to answer: Why does such a large research system produce so little, and what can be done about it?

Of the relevant systemic factors that may condition research production (see, for instance, Ngozi et al., 2016; Cloete and Bunting, 2013; Begum, 2006), we focus on:

i. Input: we evaluate research input in three aspectspersonnel, funding and time allocated to research; and

ii. Support system: here we focus on institutions and policy, and research support services.

The choice of these two factors is informed by our conceptual framework which is based on the Doing Research Assessment (DRA) Methodology (GDN, 2017). Following this methodology, we conceptualise our assessment as illustrated in Fig. 1. On the input side, the quality of personnel, the amount of time that they are able to spend on research as well as the availability of funding

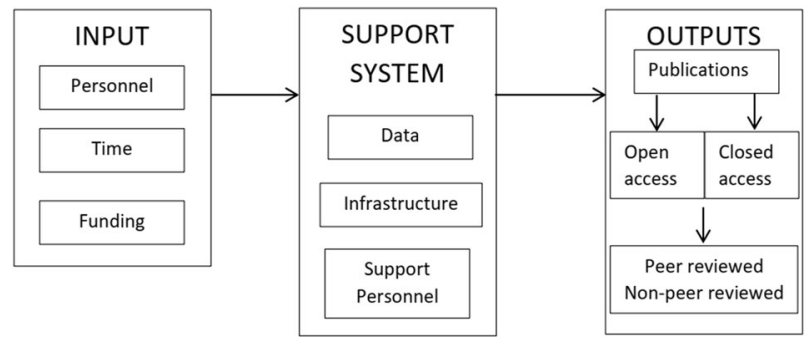

Fig. 1 Systemic factors that condition SSR outputs. The figure illustrates the conceptual framework of the study. It shows that the research system accepts inputs in the form of research personnel, the amount of time they spend on research and how well they are funded. With the data, infrastructure and support personnel provided by the research system, these inputs yield outputs in the form of open-access or closed-access research publication.

all influence the rate of SSR production. The effectiveness of these input factors is in turn conditioned by the system within which they are deployed. The most notable aspects of the system include the availability of relevant and high-quality data, physical and intangible infrastructure as well as support personnel (GDN, 2017).

We operationalise this framework through a mixed-methods design that combines the collection and analyses of qualitative and quantitative data with rigorous desk research. After describing the research context in the next section, we provide more information on the methodology. Subsequently, the findings are presented and discussed. We show that the volume of social science research production in Nigeria is quite high and has strong potentials for good quality.

The data suggest that Nigeria is the second highest producer of SSR in Africa and most of it is peer-reviewed. We estimate between 6389 and 31,943 social science researchers in the country, around $36 \%$ of whom have a Ph.D. However, most of these researchers are compelled to devote too little time to research due to distractions that arise from poor organisational research climate. The overall research landscape is also not well coordinated, largely due to the absence of a social science research council or a similar central coordinating agency. Thus, research funding is considerably limited and foreign funding comes with misaligned agenda that tends to render SSR irrelevant to local needs. These findings highlight the strong need for an improvement in the research environment, starting with the supply of high-quality research support services particularly in the universities and research institutes. There is also a glaring need for a national research policy as well as a central state-led institution dedicated to research management.

Our study extends the previous literature on social science research in Africa. In particular, as far as we know, this study provides the most rigorous evaluation of social science research input and support system in Nigeria so far. This constitutes a much-needed addition to the research on research literature in Nigeria (Ngozi et al., 2016; Nwaka, 2000) and sub-Saharan Africa (Sooryamoorthy et al., 2018; Confraria and Godinho, 2015; Cloete and Bunting, 2013; Obikeze, 1979). Moreover, we go well beyond bibliometric analyses which provide only an aggregate view of the SSR landscape (e.g., Ezema et al., 2017; Mouton, 2010) to explore some of the characteristics of the research system that condition its output. The use of rich qualitative data allows us to draw a link between the attributes of the SSR system and the volume, relevance and visibility of its output. To the extent to which these attributes are amenable to policy, the results of this paper are particularly useful for policy. 


\section{Empirical context}

With a projected ${ }^{1}$ population of over 186 million in 2015 (NBS, 2017), Nigeria is the most populous country in Africa and the seventh in the world according to United Nations' estimates (UNDP, 2016). The country is divided into 36 states across six geopolitical zones-three in the north and three in the south. It is a former British colony that gained independence in October 1960. Following independence, the system of government followed the British model, until 1999 when an American-style representative democracy was established after three decades of military rule. Despite a number of reviews and reforms, the education system continues to follow the British model. The political structure of the country concentrates power in the central Federal Government which controls the university education system and most of the research institutes. Thus, many of the SSR activities are conducted within the structures and institutions of the state. Therefore, weaknesses in the rule of law, political stability, government effectiveness and corruption affect the independence, objectivity and efficiency of research organisations, which in turn facilitate (or hinder) the work of researchers.

For the purpose of this study, we identified 1825 organisations that make up the SSR system and categorised them into four:

i. Higher education institutions (170)-comprising federal, state and private universities. We exclude other tertiary institutions because they are less research-oriented.

ii. Government and funding agencies (75)-comprising foreign donors, local donors, regulators, national agencies, national ministries and research institutes

iii. Private sector organisations (65) - comprising for-profit think tanks and consultancies as well as businesses that hire researchers

iv. Civil society organisations (1515)-omprising nongovernmental organisations (NGOs), opinion leaders, non-profit think tanks and the media.

The diversity of actors and the size of the country create a system in which research is highly dispersed. Moreover, as is typical of many developing countries with poorly mapped systems, there are no reliable sampling frames or databases on the research actors. It is therefore extremely difficult to compile a comprehensive list of institutions with information about the number of researchers in each. Nonetheless, we know from firsthand experience that most of the SSR produced in Nigeria emanates from universities. Comparatively, the volume of research is lower in research institutes and almost negligible in civil society and the private sector. Our assessment of SSR production is therefore heavily tilted towards the university and research institutes.

One of the most widely accepted ways of assessing research output is to use bibliometric data (Ezema et al., 2017; Mouton, 2010). However, some points need to be borne in mind when applying bibliometrics to SSR in the African context. First, research from Africa is under-reported in existing bibliographies (Duermeijer et al., 2018; Gaillard, 1992). Even Scopus, which is recognised as being one of the most comprehensive ${ }^{2}$, particularly in terms of its coverage of developing countries, excludes a large chunk of research from Africa. This under-coverage is particularly acute for disciplines in the humanities and social sciences. Second, a large number of journals local to Africa are excluded from all of the major international indexes (AU-NEPAD, 2010). Finally, while the quality of many publications is poor, there are in fact some very good journals that are not listed in any of the well-known indexes. As AU-NEPAD (2014, p161) notes:

"Scientific papers published in national journals may have low impact factors and limited distribution but this does not necessarily imply that the quality of research is poor. Frequently, papers produced nationally address national issues and aim to propose solutions, which affect national policy... To take account of the fact that national publications reflect national research performance in Africa, a bibliometric system that includes international and local journals is required."

Taken together, these points imply that the bibliographic data underestimates actual output, especially for a large country like Nigeria. Our methodology which we describe subsequently takes these points into consideration. In addition to using a relatively more comprehensive bibliographic database, we use additional data from a survey and interviews with key informants. In combination, these allow us to provide estimates of research input and output, and to discuss relevant systemic characteristics.

\section{Methodology}

As highlighted in the section "Introduction", our research approach is based on the DRA Methodology. It is a mixedmethods design that includes a desk review, a bibliometric analysis, key informant interviews and surveys. The desk-based component of the research involved a review of relevant academic literature including journals, books, reports, working papers and Grey literature. Yet, we were unable to obtain several important indicators and secondary data on the SSR system in Nigeria, notably research expenditure on social science research, and human capital for SSR. To fill these gaps, we made estimates based on the available data, and also asked key informants who have extensive knowledge of the system-for instance, an estimate of the total number of academics in Nigerian universities was obtained from a member of the management staff at the National Universities Commission (NUC).

Given that the SSR system in Nigeria is poorly mapped, obtaining accurate data on certain indicators such as the number of social science researchers would require that we undertake a census in all relevant organisations. Given the sheer size and dispersion of the research system, such census is beyond the reach of our study. The UNESCO Institute for Statistics (UIS), among other regional and national bodies, provides some relevant data but these are not necessarily disaggregated by discipline. Hence, in several places we rely on data from the 2009 Survey of Research and Experimental Development (R\&D) in Nigeria, the first and so far the only comprehensive research census in the country (NACETEM, 2010). The survey, which covered the period 2006-2007, was carried out as part of NEPAD's African Science, Technology and Innovation Indicators (ASTII) initiative (AUNEPAD, 2010). A limitation of this survey is that although it included all tertiary education institutions and research institutes in Nigeria, several institutions, especially universities, did not respond. Wherever necessary, we extrapolate this data, provide a range or an estimate, and complement with other sources.

We obtained data on research output from Scimago, an online bibliographic database that contains aggregate data on different publication types. Unlike other well-known databases like Scopus and Web of Science, Scimago is freely available and is more appropriate for our context given its wider coverage of research in developing countries. The scope of our bibliometric analysis is limited to basic indicators such as publication counts, citation and open access publications in the social sciences. We collected these indicators ${ }^{3}$ for the period 2015-2017 on four disciplinary areas that correspond to the social sciences in Scimago:

i. Business, management and accounting

ii. Economics, econometrics and finance

iii. Psychology 


\section{iv. Social Sciences}

Following the aim of this paper to understand the systemic factors that influence the rate and direction of SSR production in Nigeria, we gathered relevant information through a survey of researchers, administrators and policymakers selected across the four categories of organisations described above. First, we selected 130 organisations from the 1825 described above. We then selected individuals from these organisations by simple random sampling ${ }^{4}$. Our final sample comprises 805 individuals and the response rate is $85 \%$. There were more male and postgraduate degree holders across all our sampling categories (Table 1$)^{5}$. To complement the data analyses and gain a deeper insight into the research environment, we interviewed 17 key informants whom we purposively selected based on their individual profiles and position within the SSR landscape in Nigeria (Table 2) ${ }^{6}$.

\section{Results and discussion}

As highlighted in the section "Introduction", our aim in this paper is to provide information on the current rate of SSR production in Nigeria and provide insight into the characteristics of the system that influence it. The following discussion is organised into three parts as illustrated in Fig. 1.

Social science research output in Nigeria. From all available estimates, the volume of SSR production in Nigeria is quite high. For instance, AU-NEPAD (2014) showed that from 2005 to 2009, the country produced a total of 13,333 peer-reviewed publications in Scopus. While this is large on its own and makes Nigeria the

\begin{tabular}{|c|c|c|c|c|}
\hline Respondents & Researchers & Administrators & Policymakers & Total \\
\hline Sample & 585 & 145 & 75 & 805 \\
\hline Retrieved & 506 & 117 & 61 & 684 \\
\hline \multicolumn{5}{|l|}{ Sex } \\
\hline Male & 346 & 83 & 42 & 471 \\
\hline Female & 136 & 32 & 19 & 187 \\
\hline No response & 24 & 2 & - & 26 \\
\hline \multicolumn{5}{|c|}{ Highest qualification } \\
\hline Bachelor & 26 & 26 & 23 & 75 \\
\hline Master & 181 & 20 & 25 & 226 \\
\hline Ph.D. & 257 & 60 & 7 & 324 \\
\hline Postdoctoral & 12 & 7 & 1 & 20 \\
\hline No response & 30 & 4 & 5 & 39 \\
\hline
\end{tabular}

third-largest research producer during that time, it is far behind the top two countries: South Africa had 32,372 and Egypt had 22,955 publications (AU-NEPAD, 2010). Nonetheless, Nigeria turns out to be the second-largest producer of SSR in Africa between 2005 and 2009, producing a fourth of South Africa's publications in social science but thrice as many as Egypt's (Table 3).

Between 2015 and 2017, data from Scimago shows that a total of 4085 SSR publications were produced in Nigeria (Table 4). However, the Scimago data does not include some types of publications such as technical reports and policy briefs, which are also important SSR outputs. Our survey asked researchers to report on these other types of publications that they produced in the preceding 3 years. Figure 2 plots the share of respondents who have produced at least one publication of each type. Clearly, journal articles, conference proceedings and book chapters are the most common. This is consistent with previous research, which suggests that journal articles and conference proceedings are the dominant forms of SSR output (Al et al., 2006; Hicks, 2004). Indeed, one of the best ways in which the research system selfregulates is by peer review. It is expected that rigorous peer review helps to improve research quality and reduce unethical practices. Thus, the amount of published research that benefits from peer review are a proxy for the overall quality of outputs in a research system. It is, therefore, encouraging that around $98 \%$ of all published SSR output in Nigeria is peer-reviewed (Table 4).

We find that open access publishing is commonplace in the Nigerian SSR landscape. In our survey, nearly half of the sampled researchers published at least $40 \%$ of their output without any restrictions in the three years prior to the survey. Similarly, around one out of every three social science publications attributable to Nigeria in Scimago is open-access (Table 4). There is an exceptionally high rate of open access (OA) publishing in the field of Economics, econometrics and finance. In this field, the rate of OA publishing is $44 \%$ despite the fact that it contributes just $15 \%$ of total publications. This contrasts with the broad field of Social Sciences which accounts for $60 \%$ of all publications but has an OA publication rate of $37 \%$ (Table 4). The existence of several OA outlets such as the Munich Personal RePEc Archive (MRPA) ${ }^{7}$ and African Journals Online $(\mathrm{AJOL})^{8}$ contribute to the proliferation of OA output in economics. For instance, $14 \%$ out of the 341 SSR-related journals listed in AJOL at the end of December 2019 are in the field of Economics and Development, the third-largest share among all the disciplines.

Table 2 Background information on the interviews conducted.

\section{Type of organisation}

Universities

Research institutes

Media

Regulator

Government and funding

agencies

Civil society organisations Legislators

Total

\section{Number of interviews}

5

3

1

1

3

1

17
Remarks on composition of interviewees and timing of interviews

One had been a policymaker, two were also administrators, three were also active independent consultants, three have worked extensively with international development organisations like UNESCO, and three were senior professors. Two of them were interviewed pre-survey

One was also an administrator and had worked for an international development organisation; two had obtained their Ph.D. in Europe. One of them was interviewed before and after the survey

All interviewed post-survey

Interviewed post-survey

Interviewed pre- and post-survey

Two of them were interviewed pre- and post-survey Interviewed during the survey

After speaking with this number of interviewees, it was apparent that we had reached a point of saturation; increasing the number would only have added to the costs without necessarily adding much to the quality of information 
Table 3 Top three producers of social science research in Africa, 2005-2009.

\begin{tabular}{lllllr} 
Country & $\begin{array}{l}\text { Total } \\
\text { (all fields) }\end{array}$ & $\begin{array}{l}\text { Total (social } \\
\text { sciences) }\end{array}$ & $\begin{array}{l}\text { Business, management } \\
\text { and accounting }\end{array}$ & $\begin{array}{l}\text { Economics, econometrics } \\
\text { and finance }\end{array}$ & Psychology Social sciences \\
\hline South Africa & 32,372 & $4111(12.7)$ & $291(0.9)$ & $421(1.3)$ & $712(2.2)$ \\
Nigeria & 13,333 & $1133(8.5)$ & $120(0.9)$ & $67(0.5)$ & $67(0.5)$ \\
Egypt & 22,955 & $390(1.7)$ & $115(0.5)$ & $46(0.2)$ & $880(6.3)$ \\
Perp & $23(0.1)$ & $207(0.9)$ \\
\hline
\end{tabular}

Percentage in parentheses; numbers include only articles and review articles, and exclude editorials, letters, conference proceedings and other document types.

Source: Authors' compilation based on data from AU-NEPAD (2010).

Table 4 Social science publications in Nigeria, 2015-2017.

\begin{tabular}{lllllll} 
& Peer-reviewed & Non-peer-reviewed & Total & \% peer-reviewed & Open access & \% open access \\
\hline Business, management and accounting & 761 & 15 & 776 & 98.1 & 139 & 17.9 \\
Economics, econometrics and finance & 601 & 8 & 609 & 98.7 & 268 & 44.0 \\
Psychology & 225 & 9 & 234 & 96.2 & 58 & 24.8 \\
Social Sciences & 2404 & 62 & 2466 & 97.5 & 308 & 1373 \\
Total & 3991 & 94 & 4085 & 97.7 & 33.6 \\
\hline Source: Authors' compilation based on data from Scimago. & & & \\
\hline
\end{tabular}

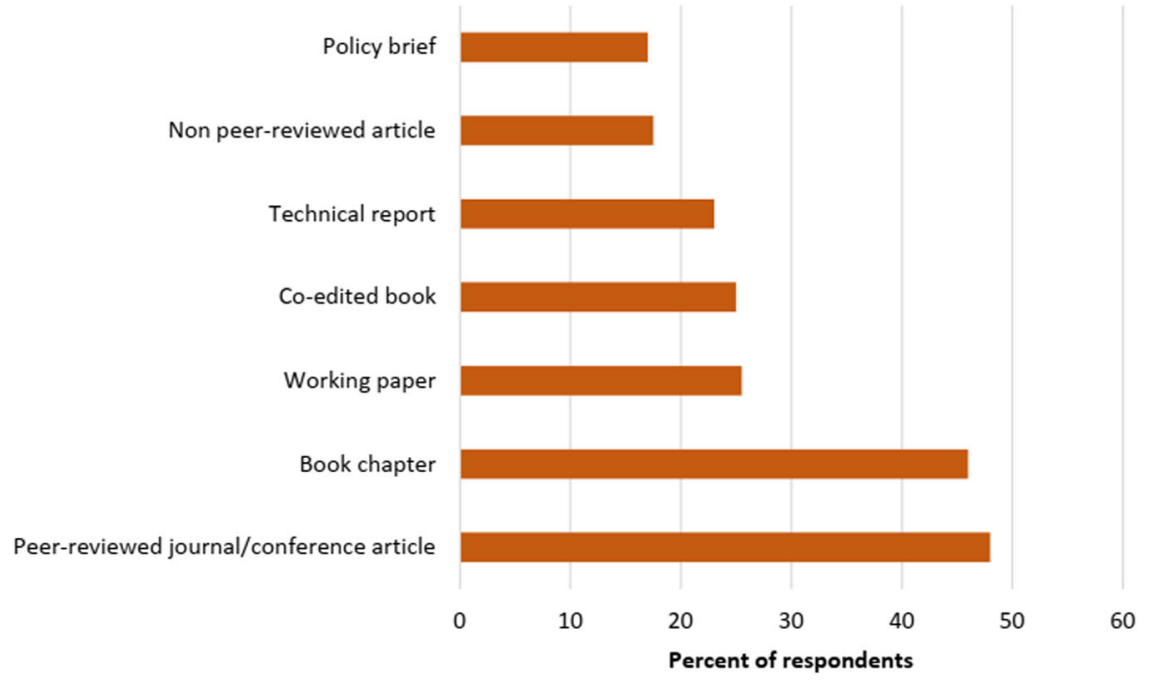

Fig. 2 Share of researchers $(n=506)$ with different types of research publications. The figure shows the distribution of different types of research publications among the researchers in the study sample. Each bar represents the share of 506 researchers that claimed to have produced at least one unit of each type of publication between 2017 and 2019.

Peer-reviewed research output in Nigeria is dominant because academic career advancement is tied to it. In universities and research institutes, the number of journal articles and conference papers produced by researchers, usually within a 3-year window, carries most of the weight in the promotion and tenure decisions. However, tenure and promotion decisions typically rely on publication counts rather than impact. This culture, although rapidly changing recently, has had three important implications for SSR production in the country. First, the incentive for highquality publications is reduced as researchers race towards the number of publications required for promotion. Secondly, the demand for predatory journals is increased because researchers feel pressured to 'publish or perish'. Thirdly, unethical practices such as plagiarism and publication slicing (where researchers unnecessarily split their research into multiple publications) are stimulated. Hence, a large number of journals published in Nigeria-or in which research from Nigeria appears-are fairly obscure (Ezema, 2010). Countering these implications requires strong and consistent policies.
A large share of local journals are not only absent from international indexes, they are also characterised by short life span, many of them not going beyond 2 years (Ifidon, 1994). In a study of the social science research landscape in Nigeria, Ezema et al. (2017) found a high prevalence of commercial publishersan alternative term for predatory publishers-among the publication outlets used by Nigerian social science researchers. One interviewee confirms this problem, stating that the NUC needs to

"get experts together in Nigeria now to accredit and reaccredit journals in the various disciplines, but I tell you it's a huge operation...We have a responsibility and we are doing something it's just that the problems are enormous."

Nonetheless, the volume of social science research production in Nigeria is obviously high and has strong potentials for good quality. However, the volume of production does not match the large size of the SSR system. For instance, a total of 3991 SSR publications amount to 2.2 publications by each of the 1825 
organisations in the Nigerian SSR system from 2015 to 2017. Even if all of the publications were produced by universities, this would be only about 23.4 publications per university in two years. Moreover, the potential for quality is hindered by several systemic weaknesses. In the subsequent sections, we turn to an explanation of some factors that may explain these observations.

\section{Systemic factors that condition social science research output in Nigeria \\ Research input}

\section{Personnel}

The 2009 Survey of Research and Experimental Development in Nigeria (NACETEM, 2010) put the total number of researchers at $17,624^{9}$. Of these, 15,739 were in universities and the remainder were in research institutes. At the end of 2017, the total number of academic staff in Nigerian universities was 62,000 according to the NUC's Nigerian University System Statistical Digest..$^{10}$ The R\&D survey data is dated and counts researchers from fewer universities compared to the more recent NUC data. However, to the best of our knowledge, it is the only reliable count of the number of researchers in Nigerian research institutes. Subsequently, we adopt the documented NUC estimate of about 62,000 researchers in the Nigerian university system and add 1885 researchers in research institutes as reported by NACETEM (2010). This yields a total of 63,885 researchers in Nigeria.

Without further data, it is difficult to reliably determine what share of these is in the social sciences. Unfortunately, even regulators do not keep such disaggregated data. For instance, a key informant from the NUC informed us that university personnel data disaggregated by discipline was not available at the NUC. There are two ways by which the number of social science researchers may be estimated from the available personnel data: funding and faculty share. Data from NACETEM (2010) suggest that SSR takes approximately $10 \%$ of R\&D funding in Nigerian universities and research institutes. If we assume a 1:1 mapping between funding and R\&D personnel, the share of social science researchers would then be about $10 \%$ of 63,885 , that is, 6389 . Assuming that the ratio of social science researchers to other disciplines is 1 , the share of social science researchers would then be about $50 \%$ of 63,885 , that is, 31,943 . In sum, these estimates suggest that as of 2017, the number of social science researchers in Nigeria would have ranged anywhere between 6389 and 31,943. Using a population estimate of 190 million in 2017, this would amount to between 34 and 168 social science researchers per million Nigerians. The 2009 R\&D Survey ${ }^{11}$ reports 5802 researchers with a doctorate degree, 155 in postdoctoral positions and 4366 studying towards a Ph.D. in Nigerian universities. Thus, a total of 5957 university researchers (38\%) already possessed a doctorate ${ }^{12}$. Of the 1885 researchers in research institutes, only 354 (around 19\%) had a Ph.D. In combination, 6311 (around 36\%) of all researchers in the universities and research institutes already possessed a Ph.D. at the end of 2007. Keeping with the estimated range of 10-50\% from before, the number of social science researchers with a Ph.D. would be between 631 and 3155 . On the lower and upper bounds, this would be around $36 \%$ of all social science researchers at that time ${ }^{13}$. It is striking to observe that the share of Ph.D.-qualified researchers in universities is at least twice as much as in research institutes. This may be connected to two factors: there are many more universities than research institutes in Nigeria, and there is a sharp contrast in the appointment and promotion structure in these two types of institutions.

Admittedly, the above estimates are based on a set of strong assumptions and are clearly dated. Unfortunately, more recent data is not available. Nonetheless, the numbers hint at a large research system compared to those of other African countries. For instance, of the 13 countries assessed in AU-NEPAD (2010, chap. 3), Nigeria had the second-largest number of researchers and also the second-largest number of Ph.D.-qualified researchers. Per million, the country had the fifth-highest number of researchers. It is therefore not surprising that Nigeria is one of Africa's highest producers of research in general, and of SSR specifically. The surprising fact is that the country's research production does not match the size of its research system. South Africa, which has a considerably smaller research system, at least in terms of the number of research organisations, produces much more research than Nigeria both in general and in the social sciences specifically. A straightforward explanation can be found in the much higher number of researchers in South Africa compared to Nigeria.

\section{Funding}

Data from the 2009 R\&D Survey (NACETEM, 2010) showed that Gross Expenditure on Research and Development (GERD) was $\$ 45.9$ billion that is USD583.2 million (2009 PPP $)^{14}$. As a share of GDP, this was only $0.2 \%$, far below the UNESCO-recommended $1 \%$ of GDP. Around $96 \%$ of the research funding was provided by the government of Nigeria. The private non-profit sector provided nearly $2 \%$ of the funding while $1 \%$ came from foreign sources. The for-profit private sector provided only $0.2 \%$ of research funding at the end of 2007. Most of the research funding (about 65\%) went to universities where $11.3 \%$ of total R\&D expenditure went to social science and humanities. In research institutes, only $6.2 \%$ of R\&D expenditure went to the social sciences. Applying these percentages to the GERD value, we find that total R\&D expenditure in Nigerian universities and research institutes was around $\mathrm{N} 29.72$ billion and $\mathrm{N} 16.14$ billion, respectively. Of these, about $\$ 3.3$ billion in universities and $\$ 1$ billion in research institutes went to SSR. As a share of GERD, this represents only about $9.3 \%$. As estimated above, the number of social science researchers in Nigeria in 2007 would be in the range between 1762 and 8812; thus, GERD on social science per researcher would be $\mathrm{N} 2.42$ million in the upper limit and $\mathrm{A} 0.48$ million in the lower range. In $2009 \mathrm{PPP}$, these would be between approximately USD 31,000 and USD 6000 .

Considering that the GERD values include salaries and wages among other things, it stands out clearly that SSR in Nigeria is poorly funded. This much was admitted by a staff of the Tertiary Education Trust Fund (TETFUND) who said about the level of funding that

"...it's not adequate to the level that we can push the economy forward but we as an institution we think that we are doing our best to encourage it."

From our first-hand knowledge of the system and some key informant interviews, we know that the contribution of foreign sources to domestic research in Nigeria is heavily underreported. A lot of the funding comes in form of grants and consultancies but in the university system where most of the research takes place, there is no national monitoring or reporting framework for foreign research funding. Even at the level of individual universities, only large grants are passed through the institution; smaller grants are offered directly to individual researchers and are therefore invisible to observations like ours.

We found out from some of the interviews that a huge amount of funding flows into the country across all disciplines, including social science. Beyond research grants provided by TETFUND, which is the primary research funder in the country, nearly all of the individual and organisational grants expended in Nigeria are from foreign donors. While this is positive in and of itself, it comes with a burden of responsibility for local researchers to follow the agenda of the funding agencies. For instance, almost without exception, calls for grants proposals are tied to research questions and objectives that are pre-determined by the donors. Generally, these questions and objectives are developed with little or no input from local researchers. Therefore, even if they seem appealing, they are often marginally relevant to local needs. In the face of scarce local funding, researchers are compelled to tune their research agenda towards these 'imported' research agenda, and ultimately produce outputs that satisfy donors but have limited local relevance. In general, over-reliance on foreign funding reduces the relevance of research activities to the Nigerian situation (Ngozi et al. 2016).

\section{Time for research}

Time allocated to research as a share of the researcher's full time is an important indicator of the state of a research system. In a healthy system, the amount of time dedicated to research activities (conducting own research, or other research production, writing, presenting, reviewing) needs to be properly balanced with time devoted to other professional responsibilities such as teaching, administration, preparing lectures, supervising, etc. Most (68\%) of the social science researchers that we sampled indicated that they did not have sufficient time for research over the last three years. Indeed, the majority of the researchers spend less than $50 \%$ of their time on research (Fig. 3). On average, the researchers reported spending only $39.3 \%(\mathrm{SE}=1.08)$ of their time on research and the typical (median) social science researcher spends only about $30 \%$ of their time doing research. This implies that if we assume 250 working days in a year, the country only realises the equivalent of 75 full days of research from the typical social science researcher.

Several factors are responsible for this low time allocation to research. Besides weak infrastructure, perhaps the most visible of the problems is the amount of distractions that arise from poor organisational research climate. Previous research (e.g., Begum, 2006)

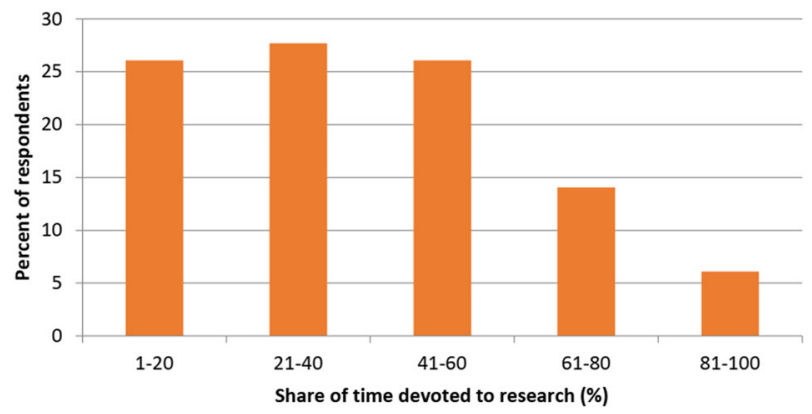

Fig. 3 Share of researchers' time allocated to research $(n=491)$. The figure shows the distribution of researchers according to how much time they devoted to research in 2019. The $x$-axis is the amount of researchers' time in increments of 20 per cent while the $y$-axis is the share of respondents that indicates spending a given amount of time on their research activities. 
suggests a strong positive correlation between organisational research climate and research productivity. Notable among the components of organisational climate, especially in the university where most of the SSR in Nigeria is prosecuted, are weekly teaching hours, number of subjects taught per week, student-teacher ratio, number of non-research responsibilities such as committee memberships, and bureaucratic efficiency. Unfortunately, the research system in Nigeria performs poorly on nearly all of these components. Most research organisations are understaffed and the few research staff has to overwork to keep the system running. The problem of inefficient grants management and other research support offices also creates a distraction for researchers. As noted by one of our key informants, who is a researcher-lecturer in Nigeria's first university,

“...not a lot of time is allocated [to research]. People do more teaching than research... and you don't get enough grants to do your research. Even when you do have research grants, I've found that all the supporting activities [are weak]. For instance personally speaking, the time you spend chasing your money [after] the grant you've already [secured] has already landed in the university's account and they've taken their overhead, is way too much. So there are distractors every now and then that researchers just have to struggle with, and those things eat into the time they have to do research. And when that happens and the time is dragging, it has a direct effect on morale, which becomes low."

\section{Research support system}

\section{Institutions and policy}

The existence of an active central institution for the management of research has several advantages. It helps to guarantee a consistent flow of funds for SSR and to ensure that national plans and programmes incorporate SSR. Moreover, such an institution sets the SSR agenda in the country and aligns it to national development priorities. In many countries, this type of institution exists as a research council, such as the Human Sciences Research Council (HSRC) in South Africa. In Nigeria, however, such institution does not exist. An interviewee referenced the Social Sciences Council of Nigeria (SSCN), which is only a self-organised community of practice comprising eminent social science scholars in Nigeria. The organisation is independent of government and does not play any coordinating role in the SSR system in Nigeria:

“...I used to know of Social Science Research Council but I don't know to what extent they regulate. I don't think there is any regulatory organ in Nigeria. We have the Nigerian Economic Society [but] they do not regulate; they only probably coordinate or disseminate research findings through their journals and through their annual conferences."

The existence of a national policy that outlines the priorities, resources and relevant institutions implicated in the promotion of SSR is closely connected to the existence of a national SSR council. Often, the policy precedes the organisation, as in the case of South Africa but the reverse may also be the case ${ }^{15}$. We found no such policy in Nigeria, from our desk review. The non-existence of the policy is confirmed by our key informants. One of them specifically said:

"[W]e don't have national research policies; even organisations don't have...I don't think we have any government organisation or a regulatory agency of government on research..."

The high difficulty in getting accurate secondary data on the current status of the SSR system is a direct consequence of the weakness in management-supervision of SSR in the country. In the absence of a coordinating council or a relevant policy, the SSR system is poorly coordinated and the level of interaction among actors is weak. Consequently, the entire system is inefficient as research efforts are often duplicated and the limited research resources are spread too thin. These problems are nicely summarised by one of the key informants that we interviewed. He noted that:

"[T]he greatest challenge on research in Nigeria is that on the average university researchers work in silos even within the same institution. These are very serious issues constraining the ability of our research to contribute to a national system of innovation. [For instance], in the Ministry of Science and Technology there are well over ten research institutes and none of them has a handshake with a corresponding research institution in the university.... and I've argued that it is a colossal waste of natural and national resources because all of this research are going on with public funds...so why can't they collaborate to strengthen our national capacity to have a robust national system of innovation?"

These observations highlight a strong need for SSR coordination in Nigeria. Efforts were made recently, based on the National Science, Technology and Innovation Policy, to establish a National Research and Innovation Council (NRIC). Although this body was not dedicated to SSR, it would at least have been a good foundation on which future interventions could build. Unfortunately, this council was inaugurated but never really took off. This leaves room for more intervention, as noted by management staff in TETFUND:

"[W]e are pushing for the creation of a national research foundation by discussing and collaborating with all the agencies and institution that revolve around research... [I]t will be a centralised role...Somebody may be undergoing a research under our own institution while another may be doing it in the health sector, but if there are no [coordinating] efforts, we will be working at cross-purposes; but collaborating will strengthen the output [of] the research and will make it more impactful...[T]here should be a national research foundation that will look at the objectives of Nigeria, how to make use of research to set national priorities, implement them and get results..."

Organisational support and administration. The capacity of a research institution to provide effective logistical support for research professionals will directly affect its overall output and quality. This logistical support includes administrative functions such as clerical work, office management, and facilitation of grant procedures. System-wide, the quality of research support services influences the strength of the research system. In Nigeria, such support services are generally available in universities and research institutes. Statutorily, all public research institutes have a Human Resources and a Finance and Accounts department that respectively manage recruitment and accounting processes. In addition to these, most universities, especially the public ones, have a Grants Management Office that centrally administers research grants.

Bearing these in mind, we asked researchers to rate their level of satisfaction with the research support services provided in their institutions. Figure 4 shows that most researchers are dissatisfied, especially with time/stress management and recruitment services. This is reflective of the situation in most Nigerian institutions, where personnel in the support offices are either poorly trained or possess insufficient competence in the provision of research support services. Many institutions also have multiple offices on the bureaucratic chain of command, thereby creating considerable inertia and inefficiency in the system. The earlier quote in the section "Research input" from a university researcher aptly illustrates the problem. A regulator also noted:

"It is one thing to have one or two good researchers in the university but it's a different thing to have a system where there are officers employed by the universities to help academics write good proposals...[I]n Nigeria...some research projects get derailed because of mismanagement of funds not because people are thieves but sometimes the professors are too engrossed in the real research work and....are financial illiterates..." 


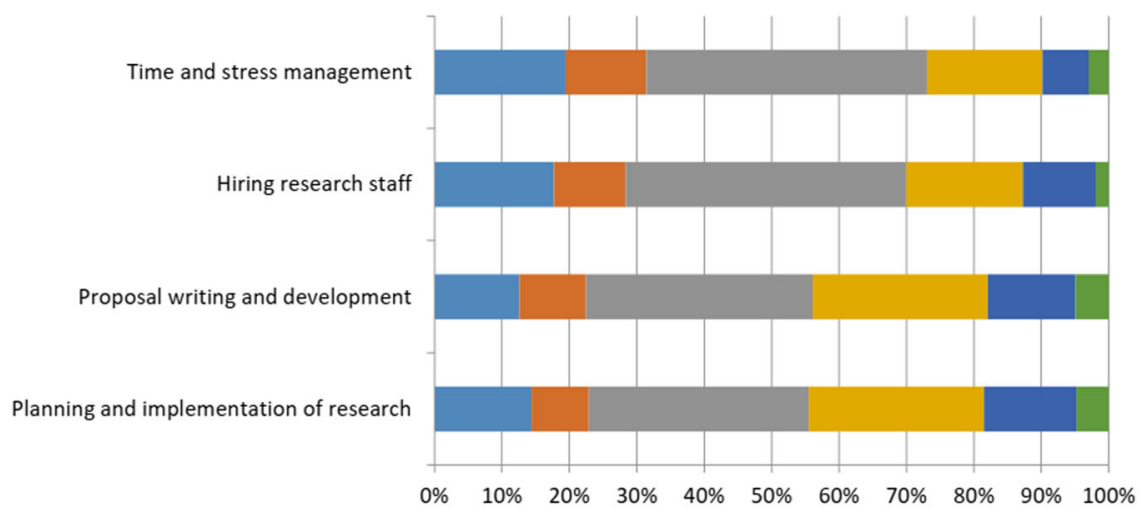

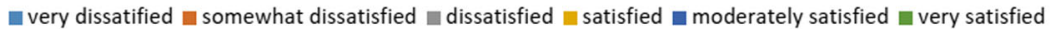

Fig. 4 Level of researchers' satisfaction with administrative support in their institutions. The figure summarises a set of Likert scale items on how satisfied researchers feel with different aspects of administrative support provided by their institutions.

\section{Conclusion}

The production of knowledge in Africa has been the subject of much enquiry particularly in the field of scientometrics. There is little research, however, on the production of social science research and its determinants. In this paper, we describe the volume of social science research production and its systemic determinants in Nigeria, Africa's largest economy and one of the largest research systems. Our point of departure is that Nigeria's research productivity does not match the size of its research system. We propose two broad explanations for this: (1) research inputs are low, mainly because research is poorly funded and researchers devote too little time to research as a result of poor organisational climate. (2) The research support system is weak. No single institution currently has a clear mandate to centrally coordinate SSR in Nigeria. Consequently, research efforts are often duplicated and the limited research resources are spread too thin. Moreover, logistical support for research is missing or inefficient in most organisations.

Three major implications can be drawn from these findings. First, there is a strong need for SSR coordination in Nigeria. A huge gap currently exists for a central state-led institution dedicated to the management of SSR. This may take the form of a national research foundation or a council. Closely connected to this is the need for a national policy that outlines the priorities, resources and relevant institutions for the production of SSR. In combination, these will help to strengthen the production of research, create funding synergies and eliminate redundancies arising from duplicated research efforts. The TETFUND, which is currently the major domestic funder of research, is wellpositioned to lead efforts in this direction.

Secondly, it is now necessary more than ever to create a localised bibliographic database as well as a national accreditation system similar to the one maintained by South Africa's Department of Higher Education and Training. While a large number of journals are published in the country across many university departments, no database or accreditation system for local journals exists in Nigeria. Overall quality tends to be low and, as a consequence, visibility is poor. The NUC is well-positioned to spearhead efforts in this regard through strong and consistent policies and institutional arrangements. For instance, steering the promotion system in universities beyond publication counts towards quality will incentivise the production of good quality research output. Curating research output in a localised database is particularly valuable because it will help to overcome the under-coverage of African research in existing databases.

Third, national stakeholders, including research organisations and the government, need to create an environment that supports research. This is especially true for universities where most of the research takes place. The existing culture of sabbatical leave during which academics are exempted from teaching to focus on research can be leveraged. Presently, many academics exploit the sabbatical leave to take up teaching positions in other universities in order to realise more income. Reversing this trend requires a higher level of funding for the research system, a role that the government is best positioned to play. Moreover, it may be desirable to implement an optional research leave system, that is, the possibility for a researcher to remain within their university to do research while being exempted from teaching and administrative duties. This is clearly not achievable in an understaffed research system. Finally, although they may not be a necessity in organisations that do not hire many researchers, competent research management offices are required in every university.

\section{Data availability}

The datasets analysed during the current study are available in the Mendeley Data repository: https://data.mendeley.com/datasets/ g2wstgcgwc/1. A data article describing the dataset is also published in Data in Brief and is openly available at https://doi.org/ 10.1016/j.dib.2021.106932 (full citation details in the references).

Received: 13 July 2021; Accepted: 13 December 2021; Published online: 06 January 2022

\section{Notes}

1 Projections based on 2006 census and population growth rate.

2 At the time of this study, Scopus contained $\sim 16,000$ journals compared with 9500 in the Web of Science.

3 All indicators were collected in January 2020. Given the dynamics of research output, a search today would yield slightly different results than those reported in this paper.

4 We stratified the organisations by type, size and location before the random selection.

5 Further details on the survey and the full survey dataset are available in Egbetokun and Olofinyehun (2021) as well as Olofinyehun and Egbetokun (2021).

6 The purpose of these key informant interviews was not to elicit novel information but to complement, clarify and deepen the insight from the data analysis. Therefore, without sharing the research results ahead, each interviewee was approached with a very specific set of questions, the responses to which were already directly connected to specific issues. Key issues raised by the individuals as well as patterns across interviews based on our research question were then readily established.

7 The Munich Personal RePEc Archive (MRPA) is a repository that is "intended to disseminate research papers of economists who want to make their work freely available through the RePEc network but are not affiliated with any institution that provides that furtherance" (https://mpra.ub.uni-muenchen.de, accessed 3 Jan 2020). 
8 African Journals Online (AJOL) is the world's largest online collection of scholarly journals published on the African continent. A considerable share of the publications in AJOL is open access.

9 This is the statistic reported in the latest version of the UNSECO Science Report at the time of this study (UNESCO, 2016, p. 320).

10 Retrieved from http://nuc.edu.ng/wp-content/uploads/2018/12/REVISED-April-25Statistical Digest-min.pdf on 7 Jan 2020.

11 We return to these older estimates because the detailed data was not available from the NUC.

12 If we assume a $100 \%$ throughput of doctoral students, the total number of researchers with a Ph.D. would be 10,323 , that is, around $66 \%$ of all university researchers.

13 This is because, by the NACETEM (2010) estimates, the number of social science researchers in 2007 would range from 10 and 50 per cent of 17,624, that is between 1762 and 8812 .

$141 \mathrm{USD}=78.62 \mathrm{NGN}$ in $2009 \mathrm{PPP}$, the year in which the data was collected.

15 In Nigeria, there is no national research foundation or council in the area of science, technology and innovation yet but a national policy on science, technology and innovation exists.

\section{References}

Al U, Sahiner M, Tonta Y (2006) Arts and humanities literature: Bibliometric characteristics of contributions by Turkish authors. J Am Soc Inf Sci Technol 57(8):1011-1022. https://doi.org/10.1002/asi.20366

AU-NEPAD (African Union-New Partnership for Africa's Development) (2010) African innovation outlook 2010. AU-NEPAD, Pretoria

AU-NEPAD (African Union-New Partnership for Africa's Development) (2014) African innovation outlook II. AU-NEPAD, Pretoria

Begum M (2006) Organisation climate and research productivity of teachers in higher education in India. World Sustainable Development Outlook, Geneva. pp. 227-236

Cloete N, Bunting I (2013) Challenges and opportunities for African universities to increase knowledge production. OCED, Paris

Confraria H, Godinho MM (2015) The impact of African science: a bibliometric analysis. Scientometrics 102(2):1241-1268

Duermeijer C, Amir M, Schoombee L (2018) Africa generates less than 1\% of the world's research; data analytics can change that. Elsevier Connect.

Egbetokun A, Olofinyehun A (2021) Dataset on the production, dissemination and uptake of social science research in Nigeria. Data Brief 35. https://doi.org/ 10.1016/j.dib.2021.106932

Ezema IJ (2010) Journal impact factors and the crisis of scholarly communication in Africa: the dilemma of Nigerian academics. Libr Rev 59(5):350-359

Ezema, I. J., Ugwu, C. I., \& Asogwa, B. E. (2017). An examination of the quality of social sciences journals published in Nigeria: implications for collection development. Library Collections, Acquisitions, \& Technical Services, 40(34): 71-86.

Gaillard J (1992) Science policy and cooperation in Africa. Knowledge 14(2):212-233

GDN (2017) Doing research assessments: understanding research systems in developing countries. Global development network programme document. GDN, New Delhi

Sooryamoorthy R (2018) The production of science in Africa: an analysis of publications in the science disciplines, 2000-2015 Scientometrics 115(1):317-349

Hicks D (2004) The four literatures of social science. In: Moed H (Ed.) Handbook of quantitative science and technology research. Kluwer, Dordrecht, pp. 476-496

Ifidon SE (1994) Overview of the state of Nigerian journal publishing. In: Michael W (ed.) Survival under adverse conditions: Proceedings of the African Library Science Journals Workshop. IFLA, The Hague, p 19-25

Mba D, Ekechukwu V (2019). Are Nigeria's universities hitting enough 'goals'? This Day Newspaper, Febraury 9, 2019 (https://www.thisdaylive.com/ index.php/2019/02/03/are-nigerias-universities-hitting-enough-goals/

Mouton J (2010) The state of social science in sub-Saharan Africa. World Soc Sci Rep Knowl Divid 63:67

National Bureau of Statistics (2017) Annual abstracts of statistics 2016. NBS, Abuja

National Centre for Technology Management (NACETEM) (2010) Nigeria's science, technology and innovation indicators: report of 2006/07 R\&D survey, 1st edn. Mimeo

Ngozi C, Malachy E, Christy O, Ngozi A, Patricia A, Prince A (2016) Problems of social research in Nigeria. Res Humanit Soc Sci 6(12):52-59

Nwaka GI (2000) Higher education, the social sciences and national development in Nigeria. Prospects 30(3):373-385
Obikeze DS (1979) A new approach to social research in Africa: the exchange process. Int Soc Sci J 31(4):732-740

OECD (2015) Frascati Manual 2015: guidelines for collecting and reporting data on research and experimental development. The measurement of scientific, technological and innovation activities. OECD, Paris

Olofinyehun A, Egbetokun A (2021) Dataset on the production, dissemination and uptake of social science research in Nigeria, Mendeley Data, V1, https:// doi.org/10.17632/g2wstgcgwc.1

Shah H (2020) Global problems need social science. Nature 577: 295 https:// www.nature.com/articles/d41586-020-00064-x

Thompson W (1824) An inquiry into the principles of the distribution of wealth most conducive to humane happiness applied to the newly proposed system of voluntary equality of wealth. Longman, London

United Nations Development Programme (UNDP) (2018). Human Development Indices and Indicators: 2018 Statistical Updates. USA: New York.

\section{Acknowledgements}

The study was supported by the Global Development Network (GDN), India, under the Doing Research Assessment (DRA) programme (Grant Reference Number: GDNIO/ GRANT/2018-19/050/DR/ABIODUN ADEYEMI EGBETOKUN). More details on the DRA in Nigeria can be found at http://www.gdn.int/doing-research-nigeria. We thank Andy Frost, Francesco Obino, João Costa and Daniel Fussy for constructive criticisms. We also thank participants at the GDN's 2019 Global Development Conference at Bonn, Germany (October 23-25) for useful feedback on a preliminary version of the results. We also appreciate anonymous reviewers and editors.

\section{Ethical approval}

This is not applicable for this study as human subjects were not involved in a way that could create potential harm. However, informed consent was sought and obtained from the respondents before information was collected from them.

\section{Informed consent}

In implementing the study, informed consent was a key ethical issue that was considered for both the quantitative and qualitative study. Every participant gave their consent before questionnaires were administered or interviews were conducted. Essentially, they were informed about what participation in the study would entail and each one had the option to discontinue their participation at any point. Every questionnaire was accompanied by a letter that explained the purpose of the study and the role of the implementing agency.

\section{Competing interests}

The authors declare no competing interests

\section{Additional information}

Correspondence and requests for materials should be addressed to Abiodun Egbetokun.

Reprints and permission information is available at http://www.nature.com/reprints

Publisher's note Springer Nature remains neutral with regard to jurisdictional claims in published maps and institutional affiliations.

Open Access This article is licensed under a Creative Commons Attribution 4.0 International License, which permits use, sharing, adaptation, distribution and reproduction in any medium or format, as long as you give appropriate credit to the original author(s) and the source, provide a link to the Creative Commons license, and indicate if changes were made. The images or other third party material in this article are included in the article's Creative Commons license, unless indicated otherwise in a credit line to the material. If material is not included in the article's Creative Commons license and your intended use is not permitted by statutory regulation or exceeds the permitted use, you will need to obtain permission directly from the copyright holder. To view a copy of this license, visit http://creativecommons.org/ licenses/by/4.0/.

(C) The Author(s) 2022 